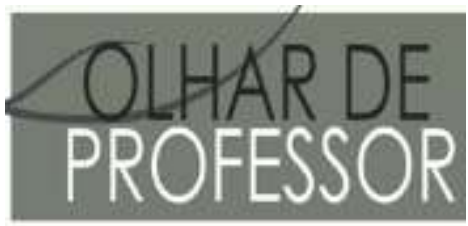

ISSN Eletrônico: 1984-0187

ISSN Impresso: I5 I8-5648

https://doi.org//0.52/2/OlharProfr.v.24.16/85.008

\title{
Um olhar para o professor no processo de ensino e aprendizagem remoto
}

\author{
Attention to teachers anxieties during remote teaching and \\ learning process
}

Una mirada al profesor en el proceso de enseñanza y paying aprendizaje remoto

Marlise Buchweitz'

http://orcid.org/0000-0003-358I-9465

Resumo: O presente estudo visa a analisar a questão do processo de ensino-aprendizagem remoto, durante a quarentena em virtude da pandemia do covid-19. Foram coletados relatos, através de formulários on-line, de professores de diferentes lugares, nos estados do Rio Grande do Sul, de Santa Catarina e do Paraná, de modo a embasar a discussão, e autores, como Olinda Evangelista, Luiz Carlos de Freitas e outros, auxiliaram no suporte teórico. O texto divide-se em reflexões sobre a Educação Básica antes da pandemia e durante a quarentena, momento no qual ainda nos encontramos. Percebeu-se uma mudança drástica no panorama da Educação Básica nos contextos trazidos para análise e destacaram-se os diferentes conflitos pelos quais os professores passam em seu cotidiano, além da já gritante desigualdade social agora intensificada, como mencionam estes profissionais. Palavras-chave: Educação Básica. Docência. Pandemia covid-19.

Abstract: This study aims to analyze remote teaching-learning process, during quarantine due to covid-19
pandemic. Narratives were collected from teachers from different places, through on-line forms, in the states of
Rio Grande do Sul, Santa Catarina and Paraná, in order to support a discussion, and authors, such as Olinda
Evangelista, Luiz Carlos de Freitas and others, support ideas theoretically. The text is divided into reflections on
Basic Education before the pandemic and during quarantine, which is already happening. It was noticed a drastic
change in Basic Education panorama in the contexts brought for analysis and it was highlighted some conflicts
that teachers go through in their daily lives; in addition, there is noticed an increasingly social inequality, according
to the teachers in this research. Keywords: Basic Education. Teaching. Covid-19 pandemic.

Resumen: : El presente estudio tiene por objetivo analizar la cuestión del proceso de enseñanza-aprendizaje remoto durante la cuarentena, debido a la pandemia de la covid-19. Se han recogido informes de profesores de distintos lugares, a través de formulários en línea, en los estados de Rio Grande do Sul, de Santa Catarina y de Paraná, para fundamentar la discusión, y autores tales como Olinda Evangelista, Luiz Carlos de Freitas y otros han apoyado en el soporte teórico. El texto está dividido en reflexiones sobre la Educación Básica antes de la

\footnotetext{
' Doutora em Estudos Interdisciplinares/Memória Social e Patrimônio Cultural (UFPel); Mestre em Letras (UFRGS). Professora. marlisebuchweitz@gmail.com
}

Olhar de professor, Ponta Grossa, v. 24, p. I-22, e-16185.008, 2021.

Disponível em <https://revistas2.uepg.br/index.php/olhardeprofessor> 
pandemia y durante la cuarentena, momento en el que nos encontramos todavía. Se ha percibido un cambio drástico en el panorama de la Educación Básica en los contextos analizados y se han destacado los diferentes conflictos por los que pasan los profesores en su cotidiano, además de la ya llamativa desigualdad social que ahora se intensifica, como lo mencionan estos profesionales.

Palabras-clave: Educación Básica. Docencia. Pandemia covid-19.

\section{Introdução}

Tão logo a quarentena se concretizou e, sem muita perda de tempo - no sentido de poucos dias depois -, as atividades escolares começaram a se delinear remotamente. Em virtude deste panorama, que se configura numa mudança obrigatória tão brusca, buscou-se realizar uma pesquisa para entender o modo como os professores se sentem com tudo isso que passaram a vivenciar e que é parte de seu cotidiano agora. Assim, o presente texto é um estudo de caso (YIN, 20I5) que visa a olhar para os professores, suas percepções e angústias e suas reflexões em relação ao papel e ao trabalho na e da Educação, antes e durante este momento pandêmico, a fim de entender o modo como estes profissionais se sentem e agem diante do novo contexto educacional e da estrutura que se apresenta - ou seja, longe das escolas e das salas de aula.

Yin (2015) destaca que o estudo de caso é um processo linear e interativo, que compreende um plano, a organização e a preparação deste plano, a coleta de dados, bem como a posterior análise deles, e o compartilhamento dos resultados. Na presente pesquisa, vislumbrou-se a questão do trabalho docente no contexto de ensino e aprendizagem remoto como uma possibilidade de reflexão e de compartilhamento de um viés a partir do olhar dos próprios profissionais envolvidos no processo. Para entender a construção deste movimento, por parte destes sujeitos, o de transferir todas as funções docentes para o universo de suas casas, portanto, era preciso organizar a lógica de trabalho e preparar os meios para que uma pesquisa pudesse se concretizar, o que se vislumbrou possível através de entrevista estruturada pelo aplicativo Google Formulários. Neste formulário, que continha três questionamentos norteadores, os professores deveriam escrever sobre como observam a Educação Básica pública, no geral; sobre a relação dos estudantes com seu percurso de busca

\footnotetext{
${ }^{2} \mathrm{O}$ presente estudo é resultado de um compartilhamento de ideias com colegas de profissão, aos quais é notório agradecer pelos debates e pelas opiniões e discussões que o momento profissional exigiu, cujo auxílio em também divulgar a pesquisa permitiu que o estudo fosse realizado. Grata, Daiane Winter, Eliara Ferraz, Liégi Jordão, Marciane Schwarz, Melânia Buchweitz Klug, Paula Raymundo, Rosane Favoreto da Silva.
} 
por conhecimento; e sobre a viabilidade e os desafios do ensino e da aprendizagem remotos durante a pandemia da covid-19.

Oliveira et al (2016) destacam a importância da fase de coleta de dados, pois nela se recolhem as informações necessárias para direcionar um estudo, apontando o que se pode e deve discutir a partir dos resultados observados nesta etapa. Para que a coleta de dados fosse possível, divulgou-se o formulário de pesquisa através de mídias digitais, o qual foi respondido por professores que se sentiram intuídos a fazê-lo, ficando claro para todos que os textos/escritos não seriam identificados e que só precisariam incluir o nome completo como participantes aqueles que assim o desejassem. $O$ instrumento a ser utilizado pelo pesquisador não pode ser aleatório (OLIVEIRA et al, 2016), de modo que uma pesquisa através de formulário com perguntas norteadoras foi a metodologia percebida para que se pudesse compreender a visão de cada um dos depoentes; a escolha por manter o anonimato dos sujeitos que se sentiram confortáveis em expor sua opinião perpassa por não colocá-los em situações que pudessem constrangê-los de alguma forma ou implicar em represálias em seus locais de trabalho, se assim fosse o caso.

Receberam-se os relatos via e-mail, de profissionais que atuam na Educação Básica, municipal ou estadual, de municípios pertencentes aos estados da Região Sul do país, Rio Grande do Sul, Santa Catarina e Paraná, a partir dos quais se pretendeu sinalizar a situação compreendida a partir do olhar daqueles que estão diretamente ligados ao processo de ensino e aprendizagem dos cidadãos e cidadãs deste país. $O$ total de relatos recebidos é de catorze, sendo dez professores atuantes em redes municipais e/ou na rede estadual do Rio Grande do Sul, dois professores atuantes em redes municipais e/ou na rede estadual de Santa Catarina e dois professores de redes municipais e/ou da rede estadual do Paraná. Este resultado foi obtido num período de 30 dias, tempo decorrido entre o início do envio dos questionários e o recebimento do último depoimento.

Conforme Yin (20I5) aponta, após o processo de coleta dos dados, precisa-se partir para a apreciação e o diagnóstico deles, processo possível, neste artigo, através da análise do discurso (ORLANDI, 200I). Com base nesta concepção teórica, portanto, destaca-se que há um discurso que se forma a partir de um lugar sócio histórico assentado em uma formação ideológica e atravessado por ela (ORLANDI, 200I). Assim, analisam-se os textos escritos pelos docentes que integraram a pesquisa observando-se que as palavras ditas são perpassadas 
de construções ideológicas, as quais contribuem para a formação do pensamento crítico e do olhar que cada um possui em relação ao espaço no qual atua. Deste modo, com base em pesquisadores da área de Educação, como Olinda Evangelista e Luiz Carlos de Freitas, buscase compreender que construção ideológica é esta, atentando-se para um movimento de enxergar como vinha sendo o ensino na escola pública antes de se chegar ao atual momento pandêmico para, então, compreender minimamente o que está sendo vivido pelos professores durante a quarentena.

No presente texto, não se fez um estudo quanto aos locais de origem dos professores, no sentido de analisar questões socioeconômicas das famílias da comunidade escolar ou dos profissionais. Intentou-se, unicamente, olhar para as sensações e as angústias que permeiam a vida profissional destes sujeitos que são responsáveis por aproximar os estudantes de um conhecimento que lhes possa fazer refletir a sociedade em que vivem, o contexto a que pertencem e as ações que podem realizar em seu meio. Independentemente das condições laborais dos professores que participaram da pesquisa, o simples fato de sentirem-se motivados a refletir sobre o que os aflige, neste momento de quarentena - um momento histórico e ímpar -, já potencializa a necessidade de atentar para a carga que se tem direcionado sobre estes profissionais. Por outro lado, salienta-se a importância de gestores da área de Educação que buscam acompanhar mais de perto as observações de seus professores, como é o caso da prefeitura de Nova Petrópolis/RS, que realizou pesquisa com os docentes do munícipio (NOVA PETRÓPOLIS, 2020). Não se está dizendo que outros lugares também não o fizeram; este é um exemplo de prática a que se teve acesso e que serve como base para a reflexão.

O objetivo principal deste artigo é pontuar o caminho que vinha sendo observado em relação à educação pública e como a mudança brusca e drástica, provocada pelo isolamento, em função da pandemia do covid-19, pode contribuir para uma nova formulação do processo educativo ou não. Com este estudo, não há qualquer pretensão de se ter respostas definitivas, já que é muito mais provável que, depois de decorrido algum tempo, possam ser percebidos efeitos positivos ou negativos relacionados a determinado fato, mas pretende-se refletir sobre o que está sendo observado pelos professores e como diferentes teóricos da área de Educação têm-se posicionado em relação às atividades remotas. Também, o presente estudo é bastante limitado no sentido de que a amostra é pequena e não se pode generalizar a análise, mas, ainda 
assim, serve como discussão para que outros estudos possam ser realizados; e, se há esse número de professores refletindo sobre o que está sendo imposto enquanto solução na Educação, é muito provável que outros mais também estejam discutindo e analisando o momento.

Destaca-se que se adotou a nomenclatura processo de ensino e aprendizagem remoto, visto que não se configura como ensino à distância o que os professores de Educação Básica estão vivendo neste momento (PEREIRA et al, 2020). A situação que se apresenta, hoje, para o ensino público é uma maneira de tentar suprir a falta que faz a escola em si, enquanto espaço físico e social, às famílias, aos aprendizes, aos docentes e às comunidades como um todo. Também, pode-se pensar a realidade dos professores agora como um movimento de responsabilizar uma categoria de profissionais para modificar radicalmente todo um modo de intermediar conhecimento e de se tornar um sujeito que não era conhecido de si mesmo. Fica o questionamento de o quanto isso interfere na relação deles com seu trabalho e no modo como dão conta das demandas que ora se apresentam.

O ato de pensar a Educação Básica pública precisa partir, principalmente, daqueles que labutam diariamente, os professores. Com contextos muito divergentes, de acordo com o lugar no qual se encontram, os professores brasileiros lidam com inúmeras questões, desde a desvalorização salarial, passando por escolas com infraestrutura precária, até a condição de, muitas vezes, não serem ouvidos ou perguntados sobre o que pode/poderia ser feito em determinadas situações.

É por causa dos professores e do universo tão novo no qual hoje se encontram, em período de quarentena, por conta de uma pandemia que atingiu o mundo, que o presente texto tem o propósito de olhar com atenção e empatia para as questões que precisam ser debatidas, trazidas à tona e dialogadas entre os pares e com aqueles que detêm, em suas mãos, o poder, digamos assim, de mudar alguma coisa, quem sabe. Muito provavelmente, as discussões que ora serão abordadas possam não ser generalizantes - quiçá não o sejam -, mas, se são levantadas, ainda que por uma minoria, é porque são parte da vivência destes profissionais. Pode-se destacar que uma educação pública de qualidade e sem qualquer discriminação, nem de professores, nem de estudantes, ou de outro grupo pertencente ao mundo das escolas, só existe realmente quando nenhum sujeito precisa manifestar qualquer angústia ou inquietação. Pode-se dizer mais: uma educação pública de qualidade parte do 
pressuposto de que todas as necessidades básicas dos cidadãos de um país são garantidas em modelo de igualdade para todos, conforme é assegurado na Constituição Federal.

\title{
Um passo atrás
}

O primeiro questionamento do formulário de pesquisa era direcionado ao entendimento que cada um dos docentes tem sobre o ensino público, para além do período pandêmico. Assim, pensando na premissa de olhar para a Educação Básica pública, a partir das angústias e inquietações levantadas por professores, inicia-se evidenciando a questão das políticas públicas, as quais norteiam, sempre, os rumos do ensino público no país. Esta questão foi referida por dois professores, em seus relatos, e para um deles:

\begin{abstract}
Vejo a educação pública sendo mantida por obrigação, como um gasto e não como investimento. Vem sendo assim nos sucessivos governos, mas o atual cortou ainda mais os investimentos, inclusive nas áreas de pesquisa que se destacaram ao longo dos anos. Quanto à participação dos alunos, sempre é a mínima possível, só o necessário para obter aprovação. Vejo como uma questão cultural já, as famílias não cobram e não participam da vida escolar dos filhos. Pior ainda, estamos vivendo um momento em que os professores e a comunidade científica vêm sendo contestados, misturando assuntos religiosos e políticos aos temas científicos e históricos do cotidiano escolar (Professor D) .
\end{abstract}

Se o percurso da Educação Básica está diretamente ligado às formas como os gestores a veem e lidam com ela, torna-se fundamental um olhar técnico que contemple também as opiniões dos professores e suas relações diretas com o ensino e com os aprendizes. Outro professor destaca que:

A educação pública está vinculada às políticas públicas federais e estaduais existentes. Essas políticas têm uma ideologia e um projeto, que podem ser bons ou ruins, de exclusão ou inclusão educacional e social. Nos últimos anos, o que tenho visto é o descaso e desmonte da educação pública e dos planos de carreira de seus profissionais. O reflexo disso, em uma situação extrema, intensifica o problema já existente (Professor L) ${ }^{4}$.

Evangelista (2016) destaca o descaso com os professores ao citar dois momentos marcantes de menosprezo pelas lutas dos docentes: quando muitos ficaram feridos devido a atrocidades cometidas durante greve em Curitiba, em 2015, e quando a Guarda Municipal de Florianópolis investiu com spray de pimenta numa manifestação em 2016. Tais ações de luta e

\footnotetext{
${ }^{3}$ Informação obtida a partir de relato escrito, em 06/05/2020.

${ }^{4}$ Informação obtida a partir de relato escrito, em 21/05/2020. 
de paralisação das atividades servem para discutir a precarização da educação e as tentativas de minimizar as retiradas de direitos, que se fazem cada vez mais presentes tendo-se o "Capital como educador", isto é, um "projeto pedagógico classista, burguês", que se coloca sobre o modo como as políticas públicas são pensadas (EVANGELISTA, 20I6), tirando dos sujeitos da escola, professores e estudantes, o protagonismo de suas constituições como sujeitos pensantes, como livres para direcionar suas escolhas de apreensão do saber.

Luiz Carlos de Freitas, em entrevista a Meirelles (20I5), discute a questão da educação na mesma linha de raciocínio de Evangelista (2016), no sentido de uma "visão empresarial" que retira poder de mediação de um conhecimento libertador por parte do professor. Ao analisar a divulgação do documento "Pátria Educadora: A Qualificação do Ensino Básico como Obra de Construção Nacional”, organizado pela Secretaria de Assuntos Estratégicos da Presidência da República (SAE), Freitas (20I5, s. p.) nos lembra de que tal viés "empresarial da Educação [...] desmoraliza os professores e aumenta a segregação escolar”. Freitas questiona a origem de tal documento e sua fundamentação, já que foi criado por entidades não necessariamente ligadas à Educação, e rebate sobre a necessidade de que os sujeitos da comunidade escolar são aqueles que precisam discutir políticas voltadas ao ensino, ou, no mínimo, entidades que os representem. O teórico continua sua análise dizendo de uma educação embasada em conceitos quantitativos, em avaliações por notas, em produtividade, enfim, um modelo no qual o resultado eficaz é um "produto" do meio em que foi feito (FREITAS, 2015 apud MEIRELLES, 2015). A analogia dos aprendizes como produtos do contexto escolar e, portanto, aptos a competir uns com os outros garante uma lógica capitalista de perceber o conhecimento que se tem e de valorizar os fundamentos educacionais que priorizam a tecnicidade, o mercado, a produção em larga escala garantindo lucro ao empresariado.

Em outro momento, Freitas (2016, s. p.) novamente destaca a questão de um desmonte da educação pública e salienta que "No plano mais específico da política educacional, entendo que é a reforma empresarial privatista, em especial na educação básica que merece atenção especial, sem demérito de outras implicações”. Para o autor, um projeto de gestão privada do ensino público e um "controle político-pedagógico do processo educativo" serão fatores primordiais para ampliar as desigualdades sociais e provocar uma destruição do magistério público como se tem hoje. 
No quesito das políticas públicas entram também as questões de infraestrutura e descaso com o saber, conforme já citados. A escola básica pública representava, para diferentes teóricos da área, um abismo entre os avanços da era da informação e o modelo tradicional de ensino; a escola era um espaço entremuros que, muitas vezes, distanciava os indivíduos de suas realidades. A expressão “redes ou paredes” (SIBILIA, 20I2) exemplifica o questionamento que muitos quase que gritavam para a sociedade - desde estudantes até profissionais. Este grito, ainda tímido, ainda tolhido em distintos locais, sinalizava uma mudança que se esperava: aproximar os sujeitos do acesso à informação, ao conhecimento, a diversas maneiras de aprender, dentro de suas realidades. Porém, a mudança não poderia ocorrer sem políticas públicas que a incentivassem, possibilitada também por recursos tecnológicos, de material, de espaço e de pessoal para atender a uma demanda totalmente distinta daquela do perfil tradicional de educação, em que um professor se coloca em frente à turma e explica um conteúdo.

Quanto ao ensino presencial, na escola pública, a questão não perpassava apenas a dimensão do conhecimento a ser mediado, mas também abrangia "falta de estrutura na escola, como, por exemplo, apoio educacional, sala de recursos, psicólogo, ou outros setores que possam dar um suporte pedagógico ao professor que está em sala de aula” (Professor K) ${ }^{5}$. Ainda, a educação pública era vista como “[...] deficitária. Já trabalhei em município onde era comum professores de qualquer formação assumirem disciplinas como artes, educação física, inglês... Eu mesma assumi disciplinas de fora da minha alçada" (Professor A) ${ }^{6}$.

Num contexto controverso entre o que se pretende trabalhar nas escolas e o que realmente se pode trabalhar, tem-se o professor quase como um malabarista, no sentido de encontrar alternativas para aproximar o tanto que há de possibilidades e recursos para mediar - conhecimento com a quantidade de recursos disponíveis em suas escolas. Um dos professores participantes da pesquisa destaca que a escola

\footnotetext{
É um espaço (ou melhor, deveria ser) onde possamos praticar a Educação de forma Integral, garantindo desenvolvimento dos sujeitos em todas as suas dimensões intelectual, física, emocional, social e cultural e de se constituir um projeto coletivo, compartilhado com todos componentes da comunidade escolar, estimulando assim a formação de sujeitos críticos e responsáveis (Professor K).
}

\footnotetext{
${ }^{5}$ Informação obtida a partir de relato escrito, em 05/05/2020.

${ }^{6}$ Informação obtida a partir de relato escrito, em 06/05/2020.
} 
Também diz que gostaria de trabalhar numa "escola que ofereça infraestrutura, em relação às tecnologias para um melhor aprendizado, para as práticas esportivas, culturais, sociais..." (Professor K). Neste sentido, precisa-se "levar em conta que nem todos têm as mesmas condições de acesso à internet, computador" (Professor A), o que revela a desconexão entre a realidade dos estudantes de nossas escolas, ou seja, "temos que pesar o abismo das diferenças sociais" (Professor C) ${ }^{7}$.

Além dos problemas apontados, através da pesquisa, se percebeu que há outras questões culturais que permeiam o universo de trabalho dos profissionais da Educação:

\begin{abstract}
Infelizmente, somos, muitas vezes, desrespeitados, e não só pelos alunos, trata-se de um efeito dominó: o Sistema nos desrespeita por não nos dar o devido valor; se o professor faz greve: é preguiçoso; se dá nota baixa: não ensinou direito; se "xinga" o aluno: é porque pegou no pé... É preciso muito amor e devoção para continuar na profissão sem titubear (Professor E) $)^{8}$.
\end{abstract}

O desrespeito citado é exemplificado quando há discrepâncias entre as realidades escolares e as questões salariais e de infraestrutura, dependendo do munícipio ou do estado em que cada professor atua. Outra depoente, que atua, além da rede municipal, também na rede particular de Educação Básica de sua cidade, faz um comparativo entre as duas realidades, salientando os problemas de infraestrutura e de falta de professores que observa na escola pública; porém, ela percebe o esforço dos professores que usam a criatividade e fazem muito com o pouco que têm, além do fato de os estudantes da escola pública terem um espírito muito mais de cooperação enquanto que, na escola privada, há um espírito de competição (Professor I) ${ }^{9}$.

Outra questão que já está um pouco imbuída, também, neste contexto, quando se fala sobre a desvalorização do profissional pelo sistema e pela sociedade num geral, está num contexto mais micro, o das famílias em relação às escolas. Segundo uma das professoras, não havia "total conhecimento, por parte dos pais, em relação a seus filhos" e pouca "parceria entre família e escola", o que dificultava bastante o ensino e a aprendizagem, já que um professor lida com "mais dez ou vinte diversidades em sua sala de aula” (Professor F) ${ }^{10}$.

\footnotetext{
${ }^{7}$ Informação obtida a partir de relato escrito, em 07/05/2020.

${ }^{8}$ Informação obtida a partir de relato escrito, em 04/05/2020.

${ }^{9}$ Informação obtida a partir de relato escrito, em 12/05/2020.

${ }^{10}$ Informação obtida a partir de relato escrito, em 05/05/2020.
}

Olhar de professor, Ponta Grossa, v. 24, p. I-22, e-16185.008, 2021. 
Uma terceira linha de raciocínio apontada pelos professores diz respeito ao próprio processo de aprendizado por parte dos estudantes. Assim, ainda que se tenha a reflexão sobre o professor como mediador, uma das professoras destaca que "O professor é muito mais [do] que um mediador, é elementar que se faça presente na exposição dos conteúdos e na construção do saber do educando" (Professor E). Isso ocorre porque, muitas vezes, o educando traz consigo "problemas enfrentados no que tange ao aprendizado geralmente de caráter familiar" (Professor K).

Muitas dimensões problemáticas foram reveladas a partir da pesquisa, que demonstraram a desigualdade social existente nos contextos escolares dos quais os professores são provenientes. Ainda que não se possa generalizar a argumentação aqui trazida para todas as realidades sociais dos estados da Região Sul, de onde são os docentes que participaram com suas perspectivas e escritas, destacam-se alguns sentidos para a educação pública: espaço de luta, lugar de diversidades culturais, de infraestrutura precária, de inúmeras necessidades de pessoal e de recursos, enfim. Tais sentidos percebidos através das palavras de professores e de teóricos da área da Educação servem para que não se deixe de pensar a escola, pensar os sujeitos que dela fazem parte e buscar direcionar a eles algum momento de voz e vez na pauta do debate que discute o futuro do ensino no país. Toda esta dimensão apontada refere-se, então, à etapa anterior ao período da quarentena, ou seja, até meados de março, enquanto se tinha o ensino presencial no formato como se conhecia.

\section{A Educação Básica pública durante a pandemia}

As dimensões sobre o processo de ensino e aprendizagem remoto vão desde uma imposição feita aos professores para justificar o recebimento dos salários, perpassando por adequação de modos de ver a educação neste período e de recursos pessoais para poder melhorar as formas de passar material aos estudantes, até chegar à questão da desigualdade social e das relações entre a família e o estudante. De certo modo, o que os professores veem e sentem sobre as atividades remotas não se distancia muito do que percebem também sobre o ensino presencial na escola pública.

$\mathrm{Na}$ maioria dos locais, no Brasil, percebe-se que a quarentena iniciou em meados de março para estudantes e professores. Deste modo, logo se iniciou a pensar em como dar prosseguimento para as atividades, tanto para não comprometer o período letivo, conforme 
possível, quanto para não deixar os profissionais parados, já que não se encontra justificativa - segundo os discursos que chegaram para os professores - para manter pagamento de salário de funcionalismo público que não esteja em efetivo exercício e, para esta expressão, entendese o exercício de cumprimento de carga horária diária comprovada. No relato de uma das professoras depoentes, tem-se que "[...] a Secretaria de Educação destacou que, como servidores públicos, temos o dever de 'servir' ao município” (Professor J, aspas no original) "', o que implica numa sinonímia que potencializa uma interpretação um tanto restritiva, já que equipara a profissão de professor a um mero ato de servir. Nesta mesma linha de cobrança, há "[...] gestores falando e cobrando da gente 24 horas por dia, finais de semana, dias de semana, manhã, tarde e noite, sem sossego" (Professor L).

Observou-se que a retomada, no entanto, não foi igual em todos os locais, dos quais os professores que deram seu depoimento são originados. Três professores relataram estar em atividades remotas já no início de abril, sendo que as reuniões com as equipes gestoras, quanto ao seguimento das atividades, já aconteciam logo após o início da quarentena, enquanto outros só iniciaram as atividades remotas bem mais tarde, quase ao final do mês de maio ou início de junho. Um exemplo é a rede estadual de ensino do Rio Grande do Sul, cuja quarentena passou a vigorar a partir de 19 de março (SCARTON; KANNENBERG, 2020), porém as atividades seguiram de modo remoto para os estudantes e foram antecipadas as férias de inverno para o mês de maio, tendo-se, então, uma parada efetiva para discutir os rumos do processo e retomar as atividades remotas no início de junho (CORREIO DO POVO, 2020).

Pensando-se especificamente na questão dos professores no processo de ensino e aprendizagem remoto, observa-se o fato de que os profissionais precisaram abarcar uma gama de situações diversas. Nos relatos, têm-se a necessidade de comprar recursos extras, como uma impressora para escanear material, e os desafios enfrentados para gravar vídeos e tornar as atividades mais acessíveis aos estudantes (Professor A). Por outro lado, segundo o Professor F, este é "[...] um tempo atípico [...] [em] que nós professores nos deparamos com uma situação totalmente nova, que gera conflitos: escola x família, alunos, filhos”. Estas são exemplificações do universo novo no qual os professores se encontraram a partir do início da quarentena e, com as atividades remotas, tiveram que ampliar seus recursos pessoais e

\footnotetext{
"Informação obtida a partir de relato escrito, em 01/06/2020.
} 
conciliar e dar conta de atender a todas as demandas que passaram a ser exigidas, desde atender aos aprendizes até atender aos contextos familiares. Corroborando com esta ideia, também se destaca que

[...] nesse momento, estamos tentando criar vínculos escola e família, tentamos pensar nosso papel, mas tem a pandemia, somos indivíduos que sentem dores, que adoecem, que têm pessoas para cuidar, que têm situações de necessidades próprias... Então, tem tanto envolvido e ficar pensando só sobre como me sinto porque algo não saiu do jeito que eu esperava é diminuir o tamanho do problema (Professor J).

Para alguns, o ensino remoto é um momento de, talvez, distanciar, ainda mais, o aprendiz de uma busca por conhecimento técnico e científico, já que

\begin{abstract}
[...] acredito que os alunos do Ensino Fundamental não têm maturidade para EAD ${ }^{12}$. Sabemos que a Internet está aí, uma ferramenta sem precedentes, cheia de informações muito úteis, que auxiliam muito na Educação, no entanto o aluno - em geral - tem cada vez menos autonomia e interesse na Educação formal, no conhecimento em si. As redes sociais são muito mais atrativas, funcionando como armadilhas, que prendem o indivíduo (Professor E).
\end{abstract}

Para outros, tem-se um reflexo do que já vinha acontecendo no ensino presencial e o panorama atual serve para revelar de forma mais atenuante tal percepção:

Estamos fazendo o possível para continuar este processo de forma remota [e] precisamos, obrigatoriamente, da ajuda da família. Sofre, principalmente, a família que delegava tal responsabilidade [a de ensinar] somente à escola [...]. $O$ aluno que faz suas tarefas adequadamente na escola o fará em casa. $O$ aluno que tem apoio e estímulo da família é mais produtivo (Professor F).

Também, têm-se professores que destacam preocupações em relação ao retorno das tarefas que são repassadas aos aprendizes. Com tantas outras angústias já rondando a vida destes profissionais, ainda as questões relacionadas à educação servem para tirar o sono: “[...] sou bastante cobrada no que posso fazer quanto aos estudantes que não devolvem as tarefas e me questiono constantemente se minhas aulas não são atrativas e o que posso fazer para melhorar" (Professor J).

Neste sentido, sobre o retorno das atividades por parte dos aprendizes, a Prefeitura Municipal de Nova Petrópolis (2020) divulgou pesquisa com os professores, na qual $77 \%$ dos profissionais da rede participaram, destacando que, na data de 05 de maio, "32,4\% dos professores, até então, não têm retorno dos alunos/famílias, 39,8\% de menos da metade, 39,8\%

\footnotetext{
12 Observa-se que, neste relato, tem-se o uso da nomenclatura EAD, a qual se deixou conforme o original. Quando isto aconteceu em outros relatos, também se deixou da forma como foi escrito pelo professor.
} 
de mais da metade dos alunos e apenas 5,6\% têm retorno de todos os alunos". Em outro resultado da pesquisa, destaca-se que " $50,9 \%$ informaram que a obtenção de retorno dos alunos é a maior dificuldade" (NOVA PETRÓPOLIS, 2020). O Professor I também citou que, em sua escola, a média de estudantes é de 25 por turma, sendo que de 13 a 18 deles têm retornado as atividades ${ }^{13}$. Em muitos locais, as atividades são disponibilizadas de forma impressa nas escolas e retiradas pelas famílias, o que aumenta a proporção de estudantes sem acesso à internet atingidos pelas tarefas escolares (Professor A; Professor E; Professor $\mathrm{G}^{14}$; Professor $\mathrm{H}^{15}$ ).

Outra professora contempla todas as questões levantadas anteriormente em seu depoimento:

Acredito que o ensino à distância veio em meio a essa pandemia para reforçar o papel fundamental do professor e da escola, pois a educação também é convivência. [...] Na verdade, o EAD proporcionou uma nova realidade nos lares, a rotina mudou: os filhos não vão para escola, mas as aulas continuam em casa; os pais dizem que não têm tempo para ajudar e acompanhar seus filhos na aula EAD e também não conseguem estabelecer uma rotina com seus filhos. Portanto, o momento requer muita reflexão e não querer achar culpados. Tudo é novo, tanto para pais, alunos e professores (Professor B) ${ }^{16}$.

Para o Professor D, para um ensino remoto efetivo, "seriam necessários investimentos em como proporcionar o acesso às plataformas de estudos e ainda entregar as tarefas aos alunos sem acesso à internet”. Também, é necessário levar em conta que "[...] há problemas relacionados à situação familiar, à questão socioeconômica, ao acesso às tecnologias, às especificidades de aprendizagem de cada aluno, entre outros” (Professor L).

Há, ainda, percepções que envolvem outras questões, pelo momento atual ser, também, um tempo no qual “[...] há, com certeza, outras aprendizagens 'esquecidas' pelo mundo agitado em que vivíamos, que serão tão ou mais importantes quanto os conteúdos das disciplinas” (Professor F, aspas no original). Estas aprendizagens seriam “[...] essenciais à vida, aos cuidados consigo e com o semelhante, a sobrevivência, a cidadania, a solidariedade, as

\footnotetext{
${ }^{13}$ Informação obtida a partir de relato escrito, em 12/05/2020

${ }^{14}$ Informação obtida a partir de relato escrito, em 05/05/2020.

${ }^{15}$ Informação obtida a partir de relato escrito, em 04/05/2020.

${ }^{16}$ Informação obtida a partir de relato escrito, em 06/05/2020.
} 
práticas mais simples dentro de casa, como preparar seu alimento, a higiene, a cooperação mútua" (Professor F).

Em relação a esta temática, fica o questionamento de se tais aprendizagens esquecidas não fazem/faziam parte do processo de ensino presencial, já que aparecem no depoimento de um professor. É provável que se tenha aqui uma lógica que remete não a um ensino remoto, mas a uma ideia de deixar que este momento sirva para que os estudantes, juntamente com suas famílias, possam se permitir às aprendizagens sobre as quais escreve esse professor. Dito de outra forma, ainda que os professores estejam trabalhando de modo remoto para atender aos estudantes, as tarefas e atividades pensadas talvez devessem focar nestas aprendizagens citadas por esse professor. Tal pensamento, manifesto quase que na mesma lógica, é destacado por outro professor: “Acredito que o mais viável, neste período, seria que elas [as crianças] tivessem o afeto de seus familiares e aprendessem sobre valores e outras coisas importantes para suas vidas, que geralmente os pais dizem 'não ter tempo' para ensinar” (Professor A).

Lebedeff (2020, s.p.) lembra que "Crianças querem brincar, interagir, jogar. Crianças estão presas em casas, às vezes, só com adultos”. Ainda que não se tenha a dimensão de qual faixa etária de estudantes a autora fala, ela propõe um pensamento que lhe ocorreu:

[...] se não era de, no início do isolamento, o Ministro da Educação ter dito: - Parem tudo! Ninguém mais vai se preocupar com conteúdo, ninguém será avaliado: as escolas serão responsáveis pelo apoio a crianças e famílias. Temos que minimizar o sofrimento do tempo de isolamento!

A angústia dos profissionais direciona-se também à obrigatoriedade de envio de planejamentos e de aulas que enfocam no conteudismo e aos critérios burocráticos de cumprimento de carga horária. $O$ quanto dos anseios dos professores, hoje, é considerado quando as lideranças nacionais refletem os rumos da Educação é algo a questionar, com certeza. Em meio a essa nova rotina, conflituosa, diferente e, muitas vezes, cansativa, as perguntas que se fazem também contribuem para que haja preocupação com a saúde mental, a vida e a aprendizagem dos educandos:

[...] ० que eu considero viável é repensar essa "necessidade" dos órgãos gestores do cumprimento do calendário escolar, do cumprimento dos 800 dias letivos etc. $O$ que se garante mantendo essas normatizações instituídas e cristalizadas? Com certeza, não é o direito à aprendizagem dos alunos (Professor L, aspas no original).

Carminatti (2020, s.p.) destaca sobre os debates por parte de órgãos e entidades ligados à Educação no estado de Santa Catarina, nos quais se buscam alternativas para 
“questões como a sobrecarga dos professores e a exclusão de parte dos estudantes", o que demonstra ciência, por parte das gestões, em relação a esta problemática, também apontada pelos professores. Ainda, na mesma linha de uma preocupação com a exigência do cumprimento de uma carga horária anual, como apontado pelos professores, a autora destaca que "mais importante do que o cumprimento das 800 horas letivas previstas em lei, é priorizar o aprendizado e a saúde física e mental de professores e estudantes" (CARMINATTI, 2020, s.p.), o que já é um importante avanço nas discussões e uma possibilidade de um entendimento de que a saúde, tanto dos profissionais quanto dos aprendizes, pode estar à mercê de fragilidades.

Retomando o pensamento que direciona o ensino remoto para um afobamento, uma corrida em tomadas de decisões, por parte de gestores, quase como uma forma de talvez mostrar serviço à comunidade ou de dizer para as famílias algo como "a escola está aqui para ampará-los”, poder-se-ia remeter à possibilidade acelerada, em função da pandemia, de deixar que a economia, o capital e os grandes detentores de entidades educacionais privadas tenham o controle e a gestão da educação pública. Como já apontado nas discussões trazidas para o texto, a partir da leitura teórica de Luiz Carlos de Freitas, antes do período da pandemia, de uma precarização da educação pública e uma transferência para a gestão privada por interesses monetários, Pereira et al (2020, s.p.) salientam a corrida que entidades privadas estabeleceram para atender todas as etapas da Educação Básica com o ensino à distância e citam o "Todos pela Educação” como um “[...] movimento de monopólios empresariais que atua na educação brasileira desde 2006, e juntos intervêm sobre a política educacional por meio de secretarias de educação". Para os autores, tais grupos privados veem que

[...] uma parada no tempo estorvaria o movimento de produção e reprodução do capital, desse modo, as atividades de ensino remoto vêm sendo legitimadas sob o argumento da ineficiência e inexistência de estratégias do Ministério da Educação (MEC), crítica com a qual o Conselho Nacional de Educação (CNE) concorda [...] (PEREIRA et al, 2020, s. p.).

Neste sentido, a prática adotada seria a da comparação de "aulas à distância" com "não realização de aulas”, o que justificaria o ensino remoto, pois melhor fazer algo do que não fazer (PEREIRA et al, 2020). Tal argumentação levantada pelos autores remete à mesma linha 
de pensamento da obrigação do professor em "dar aulas" 17 remotas pelo fato de estar recebendo salário, conforme apontado por professores que participaram da pesquisa. Isso converge para a ideia de um ensino remoto que é muito mais de "interesse imediato" de empresas de ensino do que de "uma demanda de alunos e professores" (PEREIRA et al, 2020).

$\mathrm{Na}$ contramão de todos os relatos aqui trazidos, escritos por professores de Educação Básica que se sentiram inquietos para pensar sobre as questões do ensino público antes e no período de quarentena, Pereira et al (2020, s.p.) destacam os inúmeros "eventos virtuais (lives) e reprodução de materiais pedagógicos" disponibilizados para "inspirar professores e gestores", numa quase espécie de promoção da educação remota e de seus resultados positivos, o que "esvazia o debate político-educacional, seus fundamentos e concepções, em função da socialização de caricaturas quase automáticas das ditas práticas exitosas". Os autores ainda fazem um estudo cronológico da ascensão de programas e aplicativos de ensino remoto e destacam uma antecipação, por conta do contexto do vírus, de uma realidade social em que todos têm acesso à tecnologia, e quem não o tem é eliminado da possibilidade de acesso ao conhecimento e ao saber, uma forma de ''mitigar' as desigualdades sociais, promover uma tragédia humana da escola pública” (PEREIRA et al, 2020).

Seguindo a lógica da precarização e da curva cada vez mais ascendente das desigualdades sociais, no país, tem-se um material denso e bastante importante que discute a relação da economia com os pretextos de controle da população. Segundo Pochman (2020, s.p.), o objetivo disto paira em "deformar o sistema de regulação nacional (saúde, trabalho, educação, previdência e outros) em proveito dos interesses privados e do capitalismo de dimensão global". Neste sentido, ao se isentar de responsabilidade e ao transferir o debate apenas para o âmbito econômico, como se tem visto a todo instante, durante o período de quarentena, o Estado brasileiro manifesta seu total desrespeito para com os profissionais e para com as diversidades com que precisaria se preocupar. Incluem-se, nisto, também as gestões em todas as esferas de governo, bem como as Secretarias de Educação, as quais, em muitos casos, não atentam para o debate com aqueles sujeitos que são os responsáveis por

\footnotetext{
${ }^{17}$ A expressão é usada entre aspas, já que a prática de intermediar uma atividade via meios digitais está sendo comparada à execução da mesma tarefa em situação de aulas presenciais, segundo os autores (PEREIRA et al, 2020).
}

Olhar de professor, Ponta Grossa, v. 24, p. I-22, e-16185.008, 2021. 
fazer com que haja o movimento de ensinar e aprender e buscar conhecimento, tal como muitos professores manifestaram em suas escritas.

O Coletivo de Estudos em Marxismo e Educação (COLEMARX, 2020) chama como "falsa solução" um processo de ensino e aprendizagem remoto ou à distância. O grupo levanta a questão de que o acesso à informação e à internet é um direito, mas ressalva que tantos outros direitos essenciais à vida, "à água potável, à rede de esgoto, à energia, ao transporte" ainda não são assegurados a inúmeros estudantes pelo país. Sabendo das desigualdades sociais e de locais em que muitos estudantes não possuem acesso à internet, estimula-se que

[...] os sistemas educacionais devam desenvolver alternativas de "entrega de conteúdos" de acordo com as especificidades dos estudantes, podendo mesclar o uso de televisão, rádio, materiais impressos, jornais de baixo custo, envio de mensagens por SMS, uso de aplicativos educacionais e outros produtos (COLEMARX, 2020, p. 10).

Estas estratégias potencializam desgastes por parte das pessoas responsáveis por manter a organização de todo este processo, tais como direções e secretarias de escolas, além dos professores. Retomando a questão das necessidades básicas, que não são supridas em muitas famílias em situação de vulnerabilidade social, a responsabilidade de direcionar para as famílias a atenção em relação às tarefas escolares dos filhos, em tempos de pandemia, também incute numa sobrecarga. Estas famílias, muitas vezes, são as que não conseguem realizar isolamento social e necessitam dar conta de mais de uma demanda.

$\mathrm{Na}$ mesma lógica, também é preciso refletir sobre quais são as condições de estudo para os aprendizes em situação de vulnerabilidade social. É preciso questionar se há uma moradia adequada para todos, já que as desigualdades sociais são tantas, não importa o lugar de onde provêm os professores que participaram desta pesquisa ou os contextos dos quais partem os críticos da educação aqui trazidos para o debate.

Além desta análise, o Coletivo ainda vai ao encontro da lógica monetária que há por detrás de todo o processo de ensino remoto, já que “[...] os organismos internacionais e muitos governos e coalizões empresariais ocultam que estão em defesa do interesse das corporações educacionais e de tecnologias de informação e comunicação" (COLEMARX, 2020, p. 13).

Por todas estas questões apontadas e a partir de todas as justificativas que se ouve ou se lê sobre as tarefas à distância para os aprendizes, não se entende que as intencionalidades 
de gestores e demais atores da educação estejam incorretas. Pensar a escola como promotora de uma aproximação com mães, pais e/ou cuidadores (Professor $M)^{18}$ é também entender que a interação é necessária para que os estudantes não se sintam tão isolados, muitas vezes à mercê de famílias que precisaram manter suas funções de trabalho e que podem estar cansadas da labuta do dia e ainda precisam atender seus filhos (Professor F; Professor M).

Ainda que, em seu texto, destaque sobre o ensino superior em universidades públicas, Filordi (2020) clama por uma parada, já que não seremos mais os mesmos homens e as mesmas mulheres quando a quarentena acabar, e continuamos insistindo em velhas práticas para algo que ainda não conhecemos. Para o autor, "sejamos menos apressados, pois viver leva tempo, assim como estudar, aprender e humanizar-se” (FILORDI, 2020). Esta questão abordada pelo autor é de outra ordem, diferente do que se vinha discutindo até aqui, mas serve como um alerta: se os professores, que estão dentro de casa, passíveis de habitar um ambiente propício para o trabalho com o ensino e a aprendizagem remotos, com condições adequadas de alimentação e saúde - física, ao menos -, provavelmente, se tornarão outros homens e outras mulheres quando todo este período acabar, o que pensar daqueles que estão à mercê da sociedade, do Estado, da precarização da vida?

Colemarx (2020) lembra que somos responsáveis de algo muito diferenciado que é a solidariedade social. Como sujeitos que estão na mesma classe social da maioria dos cidadãos deste país e como sujeitos que tiveram acesso ao conhecimento e ao saber científico e acadêmico, somos, professores deste país, aqueles que poderão mediar e fazer ouvir que necessitamos, com urgência, de condições iguais para todos, sem discriminação, sem menosprezos e sem priorizar quem já muito tem e não cansa de almejar por mais. O que mais se pode querer a não ser que, mais do que tudo, o maior direito de igualdade de que se precisa é o de viver, de estar vivo, da vida. Concorda-se com o Coletivo de Estudos Colemarx (2020, p. I5) quando aponta que "[...] o objetivo fundamental de todas as políticas públicas não pode ser outro que a garantia da vida e da saúde coletiva (física e mental). Toda vida importa!”.

\section{Considerações finais}

\footnotetext{
${ }^{18}$ Informação obtida a partir de relato escrito, em 13/05/2020.
} 
O presente estudo de caso vislumbrou uma reflexão sobre como docentes de diferentes locais de atuação sentem-se em relação ao processo de ensino e aprendizagem remoto, implantado devido ao isolamento por conta do coronavírus. Suas percepções pessoais são carregadas de ideologia, visto que enfrentam cotidianamente o embate entre as políticas públicas e a realidade na qual estão inseridos. Através de questionários respondidos por professores e professoras, dos estados do Rio Grande do Sul, de Santa Catarina e do Paraná, foi possível analisar suas perspectivas frente à educação pública antes do momento pandêmico e durante o mesmo, vivido de forma tão controversa e com tantas desigualdades sociais cada vez mais atenuadas.

Ao se elencarem situações da educação pública antes do período da quarentena, todos os verbos foram utilizados no passado. Esta foi uma escolha que se relaciona com o momento de ensino presencial, até março do presente ano, no qual se percebiam todas as problemáticas enfrentadas, muitas trazidas pelos professores que participaram da pesquisa. Questiona-se se, quando as atividades presenciais retomarem, a escola continuará revelando os mesmos problemas ou se será possível visualizar nova contextualização do processo de ensino e aprendizagem na escola pública, no Brasil.

Todas as questões que puderam ser percebidas durante o período do isolamento e que dimensionaram as dificuldades e os impasses que os professores vivem precisam nortear novas práticas e políticas públicas eficazes para todos os sujeitos que contribuem para a construção do conhecimento dos estudantes, neste país. Nesta linha de pensamento, olhar para o processo de ensino e aprendizagem remoto como uma obrigação por parte do professor em virtude de estar recebendo salário remete a um pensamento que pretende diminuir a dimensão do que se está vivendo.

Por outro lado, quando se percebe uma preocupação em levantar dados sobre o potencial de estudantes atingidos com as atividades remotas, pode-se atentar para uma possibilidade de buscar alcançar aqueles que não estão retornando as tarefas. Porém, dimensionar a quantidade de estudantes em situação de vulnerabilidade social e tentar abrangê-los de alguma forma, permitindo-lhes o acesso ao material elaborado por professores, auxilia a dirimir lacunas imensas que se farão presentes no momento em que todos retornarem às salas de aula. Neste sentido, quando entidades ligadas à Educação demonstram ciência do excesso de trabalho que se direcionou para a vida dos professores, os quais também sentem 
as ansiedades e os anseios da pandemia, e manifestam preocupação em amenizar os efeitos negativos do processo em curso, tem-se a esperança de que os profissionais não estão sozinhos em suas inquietações.

Com tantas angústias e com tanta carga que se coloca, agora, sobre os ombros dos professores, fica o questionamento de como estes profissionais estarão, mentalmente, de saúde física e de potencial de trabalho, para retomar as atividades presenciais, quando assim chegar o momento. Será que o cuidado e a empatia necessária que o professor tem precisado agora está ocorrendo na medida do que deveria ser? Será que, depois, para colocar em prática todos os protocolos, que serão necessários para a volta dos aprendizes às escolas, os professores estarão leves e prontos para fazê-lo? Como muitos locais anteciparam as férias de inverno e a preocupação maior é a de cumprir as $\mathbf{8 0 0}$ horas de carga horária necessária, os professores, provavelmente, não terão descanso e precisarão, talvez, trabalhar durante feriados, como já tem sido uma política adotada durante a quarentena, a partir dos relatos recebidos.

Com o que se revela através do presente estudo de caso, espera-se que muitas gestões ainda mudem os rumos de suas práticas, já que ainda se tem um período de quarentena, o qual não se sabe quanto tempo durará. Também, fica o apelo para que os professores possam ser ouvidos e possam manifestar suas inquietações, bem como participar das decisões que estão sendo tomadas quanto aos rumos da Educação pública no Brasil. Esta talvez seja uma utopia, mas o que o professor mais sabe fazer é ter esperança de dias melhores e de condições melhores de trabalho.

Mais do que isso, refletir o que há por trás da acelerada mudança do ensino presencial para um processo remoto, sem uma pausa considerável para pensar as ações e sem criar o debate constante a partir da prática, importa em concordar com as questões discutidas por Olinda Evangelista, Luiz Carlos de Freitas e Jennifer Nascimento Pereira, bem como outros autores que levantam a questão da precarização do ensino público e de um desfoque de outras questões mais urgentes para os sujeitos da comunidade escolar. Se é preciso gritar para que se seja ouvido de que o que vale é a vida, são as vidas de todos os aprendizes, de suas famílias e de todos os sujeitos que pertencem à sua comunidade, então se grite. 


\section{Referências}

CARMINATTI, L. Retorno às aulas respeitará diferenças, mas com diretrizes gerais. In: CARMINATTI, L. Educação. 04 jun. 2020. Disponível em https://lucianecarminatti.com.br/retorno-as-aulas/. Acesso em: 4 jun. 2020.

COLEMARX. Em defesa da educação pública comprometida com a igualdade social: porque os trabalhadores não devem aceitar aulas remotas. Rio de Janeiro: Universidade Federal do Rio de Janeiro/UFRJ, 2020.

CORREIO DO POVO. Com antecipação de férias, retorno das aulas será em junho na rede pública do RS, 2020. 2 Disponível em: https://www.correiodopovo.com.br/not\%C3\%ADcias/geral/comantecipa\%C3\%A7\%C3\%A3ode-f\%C3\%A9rias-retorno-das-aulas-ser\%C3\%AI-em-junho-na-rede-p\%C3\%BAblica-do-rsI.4I7II0. Acesso em: I5 mai. 2020.

EVANGELISTA, O. Faces da tragédia docente no Brasil. In: Anais... XI Seminario Internacional De La Red Estrado - Ciudad De México, 16 al 18 de Noviembre de 2016, Cidade do México: Red Estrado, 2016. Disponível em: http://redeestrado.org/xi_seminario/pdfs/eixo3/68.pdf. Acesso em: II mai. 2020.

FREITAS, L. C. de. Conferência de Abertura - ANPEd Sudeste. In: Notícias ANPED, Unicamp, 2016. Disponível em: http://www.anped.org.br/news/entrevista-com-luiz-carlos-de-freitasunicamp-conferencia-de-abertura-anped-sudeste. Acesso em: II mai. 2020.

FILORDI, A. Por que a educação deveria parar na quarentena. In: Jornal GGN. Jornal On-line, 2020. Disponível em: https://jornalggn.com.br/a-grande-crise/por-que-a-educacao-deveriaparar-na-quarentena-por-alexandre-filordi/. Acesso em: 6 mai. 2020.

LEBEDEFF, T. A Educação do “e daí?" In: Facebook. Tatiana Lebedeff. Pelotas/RS: 6 mai. 2020. Disponível em: https://www.facebook.com/I670490652/posts/I02I5042833498845/?sfnsn=wiwspmo\&extid= uAOX9RKp2UcSrDOu. Acesso em: 7 mai. 2020.

MEIRELLES, E. Luiz Carlos de Freitas: "A lógica empresarial no ensino desmoraliza o professor". Disponível em: https://novaescola.org.br/conteudo/975/luiz-carlos-de-freitas-alogica-empresarial-no-ensino-desmoraliza-o-professor. Acesso em: I5 jun. 2020.

NOVA PETRÓPOLIS. Prefeitura Municipal. Ofício Circular $n^{\circ}$. 13/2020. Material Impresso. Nova Petrópolis: Prefeitura municipal, 7 mai. 2020.

OLIVEIRA, J. C. et al. O questionário, o formulário e a entrevista como instrumentos de coleta de dados: vantagens e desvantagens do seu uso na pesquisa de campo em Ciências Humanas. In: Anais... III CONEDU. Campina Grande/PB: Editora Realize, 2016. Disponível em: http://www.editorarealize.com.br/editora/anais/conedu/2016/TRABALHO_EV056_MDI_SAI 3_ID8319_03082016000937.pdf. Acesso em: 7 set. 2020. 
ORLANDI, E. P. Análise do discurso: princípios e procedimentos. 3. ed. Campinas: Pontes, 200I. Disponível em: https://contrapoder.net/colunas/pelo-futuro-agora-de-frente-para-atragedia-na-escolapublica/?fbclid=IwARI7sNkw lyqnYIwA9rU52sMuRfkkiPbSnCMVIgX5Ri9ixecwH2Z8M3VE4c s. Acesso em: I mai. 2020.

POCHMANN, M. Sobre o papel do estado na economia e covid-19. In: TOSTES, A.; MELO FILHO, H. Quarentena: reflexões sobre a pandemia e depois. Bauru: Projeto Editorial Praxis, 2020.

SCARTON, S.; KANNENBERG, V. Governo anuncia suspensão das aulas da rede estadual a partir da quinta-feira (19/3). Disponível em: https://estado.rs.gov.br/governo-anunciasuspensao-das-aulas-da-rede-estadual-a-partir-da-quinta-feira-19-3. Acesso em: II jun. 2020.

SIBILIA, P. Redes ou paredes: a escola em tempos de dispersão. Tradução: Vera Ribeiro. Rio de Janeiro: Contraponto, 2012.

YIN, R. K. Estudo de caso. 5. ed. Porto Alegre: Bookman, 2015.

Recebido em:

Versão corrigida recebida em:

Aceito em:

Publicado online em:

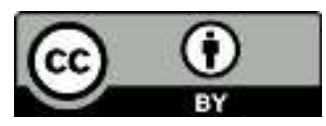

